Archivum, LXX (I), 2020, pp. 283-314

\title{
Confesar lo que no se sabe. Jacques Derrida y las políticas de la confesión
}

\author{
Juan Evaristo Valls Boix \\ UNIVERSIDAD DE BARCELONA \\ juanevaristovallsboix@gmail.com
}

Recibido: 03/09/2019

Aceptado: 23/01/20

\section{RESUMEN:}

El propósito del presente estudio consiste en abordar el carácter político del género literario de la confesión a partir de la obra de Jacques Derrida. El interés de esta cuestión radica en que, lejos de hallar en la confesión un dispositivo biopolítico de subjetivación, como hiciera clásicamente Michel Foucault, Derrida encuentra en el género un ejercicio de deconstrucción de la soberanía del sujeto y una destitución de la idea misma de género. Ello implica un desplazamiento de la confesión de su dimensión epistemológica - conocimiento y (auto)vigilancia del sujeto - a su dimensión práctica para valorarla como lenguaje performativo. De esta forma, Derrida ofrece un desarrollo insólito de la teoría de los actos del habla, donde la performatividad se caracteriza no por ser una actividad del lenguaje, sino una pasividad; no por constituir un sujeto a través del lenguaje, sino por alterarlo mediante la palabra, destituirlo. Esta estrategia pone de manifiesto el carácter político de la confesión como acto de habla, y supone un importante giro en la concepción de las escrituras de sí, anticipado por autores como 
Zambrano y Kierkegaard. Este giro implica, de un lado, que uno confiesa algo que no sabe; $y$, de otro, que la confesión es un dispositivo textual que contamina a cualquier discurso: todo texto es una confesión. Esta posición supondrá una reconsideración de la figura del autor y de la distinción vida-escritura en la que esta clásicamente se sustenta. PALABRAS CLAVE: confesión, Derrida, performatividad, sangre, soberanía, autor.

\title{
Confessing the Unknown. Jacques Derrida and the Politics of Confession
}

\begin{abstract}
:
The aim of this study is to consider the political dimension of confession from Derrida's works. Far from finding in confession a biopolitical dispositive of subjectivation, as Michel Foucault does, Derrida finds in this literary gender an exercise of deconstruction of the sovereignty of the subject, and a destitution of the idea of literary genre. This gesture supposes a displacement of confession from its epistemological dimension (self-knowledge and self-vigilance) to a practical dimension, in order to value it as a performative language. In this way, Derrida offers an original development of speech act theory, where performativity is not characterized by its activity, but rather by a sort of passivity; the subject is not self-made by doing things with words, but rather it is altered and transformed. This strategy manifests the political character of confession as a speech act, and offers an important turn in the conception of confession, anticipated by authors such as Zambrano and Kierkegaard: first, one confesses what he/she unknows; and second, confession is a textual dispositive that contaminates any discourse: every text, Derrida states, is a confession. Derrida's position implies, in this manner, a reconsideration of the meaning of authorship, and puts in question the distinction life/writing.
\end{abstract}

KEYWORDS: confession, Derrida, performativity, blood, sovereignty, author.

Maurice Blanchot inauguró El instante de mi muerte con un bello y enigmático íncipit: "Me acuerdo de un joven - un hombre todavía joven - privado de morir por la muerte misma $-\mathrm{y}$ quizás el error de la injusticia -" $(1999,17)$. Ciertamente, varias décadas antes de la publicación del libro, una escena similar tenía lugar en el ámbito de la teoría literaria. En aquellos años que 
Manuel Asensi calificó de "salvajes" (2006), a finales de la década de los sesenta, se elevó desde distintas voces una misma sentencia de muerte: la muerte del autor. Son conocidos, entre otros, el texto de Michel Foucault "Qu'est-ce qu'un auteur?" (Foucault, 1994), el artículo de Roland Barthes "La mort de l'auteur" (Barthes, 1984) o los desarrollos a tal propósito que Derrida incluyó en La voix et le phénomène (1967). Un concepto relativamente joven, de apenas algún siglo de edad, se consideraba agotado y deslegitimado como herramienta de lectura, y otros dispositivos más sofisticados, como la écriture, el discurso y sus funciones o el nacimiento del lector, venían a relevarle en su carácter estructural del texto. No obstante, y con una aguda y desconcertante semejanza con el cuento de Blanchot, el concepto de autor sobrevivió ante esa suerte de pelotón de fusilamiento teórico, y, reformulado y reinterpretado, sigue siendo un elemento o un problema clave de los estudios literarios en las últimas décadas: sigue planteando el problema de los vínculos entre la vida y la obra, la obra y el contexto, el texto y su afuera, y es capaz de hacerlo a través de aquello que pretendía venir a relegarlo en su autoridad hermenéutica: el texto solo, su corpus, que no deja de remitir a él, de reenviar o prometer su existencia. En suma, el autor ha sido, en términos de Blanchot, "privado de morir por la muerte misma": es el estilema 'la muerte del autor' el que ha dado vida teórica y debate científico al concepto de autor, que no puede ya librarse de su muerte para vivir.

¿En qué consiste, pues, esa forma de vida que está atravesada por la muerte, esa experiencia de sobrevivir a los envites de la muerte? Si la vida, habitada por la muerte, ya no se opone a ella, sino que está trabajada en su interior por esa forma eminente de alteridad, ¿cómo entender la vida y la muerte, la vida-la muerte? Es decir, ¿cómo pensar la herida? Todas estas cuestiones han de afectar de algún modo al estilema de 'la muerte del autor', a saber, al descrédito posestructuralista en que cayó la forma de interpretación que hace descansar la legitimidad hermenéutica de un texto sobre la figura que, bajo cierta perspectiva, sería su 'origen'. 
Nuestro propósito será abordar estas cuestiones a partir del motivo de la sangre y la herida en el pensamiento de Jacques Derrida, motivos que se ensayan en sus reflexiones sobre la autobiografía y la confesión. La relevancia de estas propuestas teóricas no solo radica en su distanciamiento de un pensamiento habitual sobre la confesión y la autobiografía en la filosofía y la teoría literaria contemporáneas, sino también en sugerir una concepción del autor más allá de la vida y la muerte, y 'la muerte del autor'.

Ciertamente, Derrida fue uno de los insignes promotores de esta proclama filosófica cuando, en su crítica temprana a la intencionalidad como presencia del querer-decir en la fenomenología de Husserl, observaba que la ausencia del autor, bajo la forma de la muerte, del olvido o del desconocimiento de sus propósitos, no privaba al texto de sentido o de intencionalidad: al contrario, era la condición de posibilidad para que este tuviera un querer-decir. Escribe Derrida:

L'absence totale du sujet et de l'objet d'un énoncé - la mort de l'écrivain ou/et la disparition des objets qu'il a pu décrire- n'empêche pas un texte de 'vouloir-dire'. Cette possibilité au contraire fait naître le vouloir-dire comme tel, le donne à entendre et à lire. $(1967,104)$.

Sin embargo, es el mismo Derrida el que, más de treinta años después, ofrece en distintas obras una posición teórica que exige, al menos, una revisión del acta de defunción del autor. Así, en una entrevista radiofónica de 1998 afirma sin ambages: "Estoy convencido de que, en cierto modo, cualquier texto es autobiográfico" (1998). Más aún, en una conferencia sobre el perdón, señaló igualmente que "on écrit toujours pour se confesser, on écrit toujours pours demander pardon" $(2012,70)$. En fin, y por ofrecer una última referencia, en su "Circonfession" (1991) reconoce que toda su obra es algo así como un "opus autobiothanatoheterographique ininterrompu" (§40). En diversos trabajos de los años noventa, pues, no solo el autor no está muerto en el pensamiento 
de Derrida, sino que habla de su vida y de su intimidad en todas y cada una de las obras que escribe. Para mayor asombro, con este gesto de resurrección Derrida emula a otro ilustre asesino o sepulturero de autores. Efectivamente, se trata de un Nietzsche que, en Más allá del bien y del mal, sostiene también una generalización de la autobiografía: "Poco a poco se me ha ido manifestando qué es lo que ha sido hasta ahora toda gran filosofía: a saber, la autoconfesión de su autor y una especie de mémoires no queridas y no advertidas" $(1979, \S 6,26)$.

Así, partimos en este estudio con la hipótesis de que esta generalización de la autobiografía como forma de escritura ha de implicar un pensamiento otro del autor, o una suerte de eso que Burke denominó el "retorno del autor" (1992). Con el fin de analizar esta propuesta teórica, examinaremos primero distintas concepciones contemporáneas de la escritura de sí, expondremos en segundo lugar los rasgos principales que definen el género de la confesión en el pensamiento de Jacques Derrida y, en tercer y último lugar, apuntaremos una concepción del autor que está más allá tanto de su muerte como de su vida como garante de sentido de un texto.

\section{Confesiones de un policía}

En el panorama contemporáneo existen, al menos, dos líneas de investigación acerca de la confesión, como puede desprenderse del trabajo de Llevadot (2015): la primera, quizá la más conocida, se caracteriza por ofrecer una crítica a cualquier forma de relato de sí, y cuenta con dos exponentes principales. El primero de ellos es Michel Foucault, quien concibe las escrituras de sí (diarios, autobiografías, confesiones) como un dispositivo anatomopolítico en el seno de la hermenéutica del sujeto que compone a partir de los años 80, especialmente en textos como la serie de conferencias Tecnologías del yo (1996). Allí, la confesión se comprende como una tecnología del yo heredada del cristianismo en que tiene lugar un proceso autoinducido de subjetivación y autocontrol: el sujeto construye narrativamente la verdad sobre sí 
y, amparado en el ya antiguo 'conócete a ti mismo', se autovigila y autonormaliza con un relato que regula y domina su interioridad, produce esta interioridad como un disciplinamiento y una normalización de sí. La confesión es una sutil tecnología textual que introduce un examen interior infinito y un enjuiciamiento de los actos, deseos e intenciones del individuo, obstinado tanto en la rectitud moral como en decir 'su' verdad.

De este modo, explica Foucault que "la nueva forma de experiencia del yo ha de localizarse en los siglos i y II, cuando la introspección se vuelve cada vez más detallada. Se desarrolla entonces una relación entre la escritura y la vigilancia. Así, se prestaba atención a todos los matices de la vida" $(1996,62)$. Con ello, la confesión sería una de las prácticas que Foucault amalgama bajo el término de la exagouresis, una forma de descubrimiento de sí mismo de la literatura espiritual cristiana temprana, que consiste en "una analítica y continua verbalización de los pensamientos llevada a cabo en la relación de la más completa obediencia hacia otro. Esta relación está configurada por la renuncia al propio deseo de cada uno y a su propio yo" (93). La práctica de la confesión y la autobiografía, concluye Foucault, se traslada del cristianismo a las ciencias humanas a partir del siglo xviII con un notable cambio: la tecnología verbal se emplea, prescindiendo de la renuncia del yo y sus deseos, para "constituir positivamente" un nuevo yo (94). Esta valoración, según la que un género literario ofrece un sofisticado mecanismo de normalización, arroja una sombra de sospecha sobre quien escribe y quien lee confesiones, como si ambas partes estuvieran aprendiendo a vigilarse y a ser normales al establecer un relato de sí mismo que les permitiera conocerse y ser cognoscibles, reconocibles. En suma, tener una identidad personal. Como si el pasaporte o el DNI fueran la forma más sofisticada, más condensada, de una autobiografía. ${ }^{1}$

1 Para un examen más detallado de la autobiografía como tecnología del yo y su lugar en la hermenéutica del sujeto foucaultiana, puede resultar útil recurrir a Luque Amo (2017). 
El segundo exponente de esta renuencia o condena de las escrituras de sí es de ascendencia marxista, y encuentra sus más ricos desarrollos en el pensamiento de autores como Adorno o Kracauer. Estos autores recelan de los biorrelatos en tanto que presuponen una interioridad individual de ascendencia burguesa que permite la conservación de ciertos privilegios de clase e impide una conciencia crítica con las relaciones de dominación que los generan. Además, valoran que las biografías y los diarios personales no son sino una forma de consumo de identidad personal que alimenta la fe en el mito de la autenticidad y la originalidad personal en una sociedad industrializada y tecnificada donde el capitalismo ha hecho tales cosas imposibles. Los biorrelatos, como tendencia de mercado, confirman y conservan un sistema de opresión a través de su invisibilización, son una forma de falseamiento del individuo y una práctica del fetichismo, como Matas Pons ha señalado consistentemente (2015). Cuando Kracauer se preguntaba por qué las grandes biografías de personalidades ilustres se habían convertido en "libros de éxito" y constituían una "forma de arte de la nueva burguesía" $(2008,67,79)$, señalaba justamente que ofrecían la ensoñación de ser alguien allí donde ya era imposible serlo, y la pequeña burguesía de empleados, oficinistas y secretarias, sin nobleza de sangre ni privilegios, y sin más cultura que la de entretenimiento, podía seguir creyendo que no eran solo personal uniformado sumido en actividades monótonas, sino que podían llegar a ser algo más que un don nadie. Ante la desintegración del sujeto, o la fragmentación de la experiencia, en términos de Benjamin, el capitalismo contratacaba poniendo en venta un relato de sí que disimulara tal desmembramiento.

En esta línea, Adorno y Horkheimer se mostraban contundentes en su Dialéctica de la Ilustración al sostener que "la peculiaridad del sí-mismo es un bien de monopolio socialmente condicionado que es falsamente presentado como natural. [...] El principio de la individualidad ha sido contradictorio desde el comienzo. Nunca se ha llegado a una verdadera individuación" $(2007,168)$, sino 
que "la industria cultural ha realizado malignamente al hombre como ser genérico. Cada uno es solo aquello en virtud de lo cual puede sustituir a cualquier otro: fungible, un ejemplar" (2007, 159). Donde Foucault alertaba de los peligros de la anatomopolítica al mostrar que la constitución de un yo era la forma mejor de su control, los autores asociados a la Teoría Crítica señalan que los biorrelatos son generadores de falsa conciencia, permiten la promoción y conservación del capitalismo mediante el mercadeo de la fantasía de vivir fuera del trabajo y la intercambiabilidad generalizada; esto es, el mercadeo del mito de ser único. Si con Foucault el pasaporte era la versión más actualizada y miniaturizada de la autobiografía, con Adorno o Kracauer la autobiografía comienza ocultando el precio por el que se adquiere o las condiciones sociales por las que ya no se puede escribir - porque ni hay tiempo para ello ni una vida interesante o genial que pueda ser su objeto-. O es cuestión de autovigilancia vendida como sinceridad, o es cuestión de la ideología de la autenticidad: policía o ideología. Huelga decir que las redes sociales contemporáneas han sabido aunar, bajo la forma del perfil, lo mejor de cada casa.

Ya posterior a Foucault o a Adorno, pero abundando igualmente en los reparos para con cierta escritura de sí, Giorgio Agamben valora en El uso de los cuerpos, en una sugerente lectura de Guy Debord, que hay una intensidad de la vida que reside en su clandestinidad, en aquello que en ella resulta inenarrable, y que cualquier confesión o biografía no saldrá de su idiotez mientras no sepa esquivar la enumeración de hechos banales de la vida cotidiana privada y se dirija hacia este punto ciego $(2017,21)$. De la misma forma, autores más próximos a nosotros geográficamente como José Luis Pardo (1996) o Laura Llevadot (2012) han defendido la intimidad como un momento que, por indecible, excede a los dispositivos de control de sí de esa tradición que ensaya la autobiografía y la confesión como una "autobiopolítica" (Luque Amo, 2017). Cuando la vida privada se narra, hay policía (vigilancia, normalización), pero cuando llega a sus puntos más ciegos e inenarrables, hay política (ingobernabilidad, emancipa- 
ción y extrañamiento de sí), podríamos decir. En el primer caso, se trata de privacidad; en el segundo, de intimidad. Como si lo mejor de nuestra vida quedara fuera, siempre fuera, de cualquier autobiografía o de confesiones culpabilizantes. Más allá de los biorrelatos, sugieren estos autores, hay una escritura de sí que nada tiene que ver con conocerse a sí mismo o desear un 'sí mismo', decir la verdad de uno o comprarla. Observan estos autores en la estela de Agamben que hay una experiencia de la escritura que, obstinada en esa intensidad de la vida que excede a la generalidad de las palabras, rechaza la autobiografía y busca decir lo imposible, y en ese paradójico esfuerzo se distancia críticamente de la biopolítica o de la alienación. Esta escritura rechaza el relato como forma, y se dirige hacia otros horizontes.

Sin embargo, puede considerarse que, en estas tradiciones exegéticas, sean la foucaultiana y la marxista, que condenan el biorrelato, como la afín a Giorgio Agamben, que lo promociona, opera un mismo presupuesto de base: en todas ellas la confesión es una práctica epistemológica, en ella se trata del conocimiento de uno mismo. Por ello, en unos casos la autobiografía y la confesión se condenan como mecanismos de biocontrol o alienación, y en otros, como es el caso de Agamben o Pardo, se estiman insuficientes para pensar la subjetividad. Todas estas tradiciones, que de un modo u otro recelan de la autobiografía, se sustentan en el fondo en el mismo supuesto, a saber, el carácter representativo de la escritura y, con él, en la existencia de una distinción sólida entre la vida del autor y su obra. En las escrituras autobiográficas tendría que tener lugar una adecuación efectiva entre la realidad del autor y el informe de la misma, entre vida y escritura, bios y graphein, para que el conocimiento, allende toda ficción, alcanzara el éxito de constituir un autos. La policía y la ideología solo pueden ejercerse a costa de este supuesto, que reclama una y otra vez la verdad como correspondencia y la separación sin resto de dos sustancias, la real y la copia. He aquí las limitaciones de cualquier pensamiento de lo autobiográfico que pase por estimar la escritura como forma de conocimiento. 
En cuanto a la teoría del autor, es comprensible que esta línea de investigación haya acabado en darlo por muerto. Como cuenta Foucault paralelamente en Nacimiento de la clínica (2015) y Raymond Roussell (1963), ambas obras de 1963, cuando abrimos en canal el cadáver del autor, sea en una autopsia médica o en la autopsia literaria que detalla, a título de confesión póstuma, el Raymond Roussel de Comment j'ai écrit certain de mes libres (1963), no encontramos ni rastro de su genialidad, ni de su autenticidad, ni de su interioridad: ninguna verdad o realidad con que la escritura autobiográfica pueda adecuarse o corresponderse. Solo hay, en el interior de un autor, la constitución como ser genérico de Adorno y Horkheimer: tripas, bilis y una digestión interrumpida. Solo hay, en la interioridad confesada de Roussel, un juego de azar, una mera combinatoria de palabras a través de coincidencias fonéticas. De este modo, puesto que la anatomopolítica, en sus declinaciones médica y poética, fracasa en sus propósitos al constatar que la vida del autor es inane, la teoría prescinde de la figura del autor y acuña el estilema de su muerte: al abordar el estudio solo de la textualidad, pierde, con la cuestión de la autoría, el problema de la relación entre un texto y su afuera - si lo hubiere - . Si la obra ya no da cuenta de una interioridad, puede servir para estudios sociológicos o historicistas como documento del pasado. Quizá por ello, y pese a la fulminación de la instancia autorial, el presupuesto de que es la dimensión cognoscitiva de la autobiografía la que le granjea su valor sigue en activo, y, con él, un pensamiento muy limitado de lo que la escritura es o lo que puede hacer.

La segunda tendencia de investigación acerca de los relatos de sí que se anunciaba podría remontarse a un cierto Agustín de Hipona, y encuentra su mejor momento en algunos lectores de este: Søren Kierkegaard, María Zambrano, Jean-François Lyotard o Jacques Derrida. En estos casos, lejos de descartar la confesión y las prácticas autobiográficas por su dimensión policial o comercial, estos autores comienzan su reflexión allí donde aquellos la detenían: en la confesión no se trata de conocimiento 
ni de información, no hay nada que contar, el relato de la misma es superfluo - pues no es más que eso, un cuento, un mito, una cuenta o recuento de pecados y hazañas, un cálculo del sujeto-. Estos autores insisten en esa dimensión inenarrable e indecible, ajena al campo del conocimiento, hacia la que Agamben señalaba. Comienzan a escribir a partir de la intimidad, esto es, a partir de aquello que "nos impide ser idénticos" (Pardo, 1996, 47), de todo eso cuya intensidad u oscuridad resultan inconmensurables al relato. Estos autores agustinianos encuentran, de esta forma, una política de la confesión que excede la anatomopolítica y el consumo de mitos personales, y que va más allá, por ende, del paradigma de la escritura como representación y las dicotomías vida/obra que suponía. Es en su valoración de una intimidad que se inscribe como indecodificable, enigmática o secreta, como estos autores piensan una política de sí en que el yo no se sujeta simplemente a una norma ni el autor está simplemente muerto. De esta forma, el tránsito de la policía a la política es al mismo tiempo un tránsito del conocimiento a la experiencia. Hay política de la confesión allá donde se ensaya una escritura de sí que ofrece un espacio de experimentación que desarticula el relato e impugna el carácter representativo de la palabra. En este pensamiento de la escritura no se buscará, de este modo, una identificación o una constitución, sino una transformación, un encuentro.

Analizaremos en lo que sigue los modos en que en Jacques Derrida la confesión puede albergar esta política de la transformación y, a su vez, suponer un trabajo deconstructivo de la soberanía de la figura del autor y, por extensión, de la concepción de la subjetividad de ascendencia moderna. Esta reconsideración de la escritura autobiográfica traerá otro pensamiento de lo autorial en el que esta instancia tendrá la forma de una supervivencia o sobrevida. La figura del autor, desde estos planteamientos, se torna una instancia de desbordamiento o desconocimiento de sí, el lugar en que acontece una experiencia en que vida y escritura resultan indisociables: la escritura confesional, 
por ello, se tornará una experiencia de desposesión, y ya no de autoconocimiento, normalización, o producción mítica del yo. Esta experiencia de desposesión, según la que la escritura es un espacio de pasión, y no de acción o conocimiento, se abordará en el pensamiento de Derrida y de los autores agustinianos mentados a través de un fecundo campo semántico vinculado no a la vida o a la muerte, sino a la sobrevida. Se trata del campo semántico de la herida y la sangre, a través del cual se opera el paso de la soberanía del autor a su vulnerabilidad, como en seguida mostraremos.

\section{La herida y la incertidumbre. Una política de la confesión}

Tras aproximarnos a posturas como la de Agamben acerca de la autobiografía, se impone la siguiente pregunta: si la intensidad de la vida clandestina no se puede decir, ni es traducible en la privacidad de la vida, ¿por qué escribir sobre uno mismo? ¿Por qué no claudicar ante lo incomunicable y abandonar la escritura? Derrida es uno de los pensadores que mejor ha afrontado en la filosofía contemporánea ese problema del silencio que famosamente Wittgenstein enunciaba para clausurar su Tractatus: "de lo que no se puede hablar, mejor es callar" (2003, §7). Si Wittgenstein reconocía que cualquier exceso de los límites de la lógica - y la ética y la estética lo eransuponía un absurdo y carecía de interés epistemológico hablar de ello o tratar de formularlo - lo que no siempre en su obra supuso rechazar hablar sobre ellas, sino reconocer que estaban más allá de la ciencia $-{ }^{2}$, en Derrida es justamente esta indecibilidad lo que desata la escritura, lo que la hace proliferar. Así, en su "Circonfession" se lee : "comment dire autre chose qu'un intérêt

2 Por ejemplo, en su Conferencia sobre ética (1997), Wittgenstein parece reconocer sin carga peyorativa que la ética y la estética, en tanto que se preguntan por "lo valioso" (37-38), cuestionando así el fundamento mismo del mundo, están situadas más allá de dicho fundamento. Al estar, así, más allá del sentido, es la falta de sentido lo que constituye "su mismísima esencia" (43), pues sin esta no podrían efectuar el cuestionamiento de los valores en que consisten. "La ética, de ser algo", razona Wittgenstein, "es sobrenatural y nuestras palabras solo expresan hechos" (37). 
aussi passionné que désabusé pour ces choses, la langue, la littérature, la philosophie, autre chose que l'impossibilité de dire encore" (1991, §50).

Pues si bien Derrida considera, de un modo lejanamente similar al wittgensteiniano, y siguiendo a Agustín de Hipona, que la confesión no es un gesto epistemológico y que, en ella, la información que se transmite es del todo irrelevante (entre otras cosas, porque Dios lo sabe todo), ello no es una limitación de la palabra: se trata de otra experiencia del lenguaje, una que arranca allí donde la lógica termina y que es, siguiendo de nuevo a Wittgenstein, ética y estética, pero sobre todo, con Derrida, política. No es cuestión de decir la verdad, sino de 'hacer' la verdad, de que a través de la escritura tenga lugar una "transformación", como señala Kierkegaard en su discurso “En ocasión de una confesión" (2010, 415): para él, como lo será para Derrida, la confesión ha de ser un viaje del que se vuelve transfigurado, y como tal en nada se parece al conocimiento de uno mismo o al saber de la geografía. Cuando se hace la verdad mientras se escribe, cuando la escritura y el autor son el uno la obra del otro, el uno la alteración del otro, "parler pour (ne) rien dire, ce n'est pas ne pas parler", en palabas de Derrida, "surtout, ce n'est pas ne parler à personne" $(1987,538)$. Aquí el centro de la escritura es ya esa intensidad de lo clandestino que señalaba Agamben, aquella intimidad que, siendo lo más propio, se descubre y se experimenta como lo más ajeno, como una alteración. Tanto la lógica como el régimen de representación han quedado definitivamente atrás en esta escritura de sí que busca una verdad que advenga en las palabras, y no una verdad relatable o cognoscible.

De este modo, en la confesión se trata de un "aveu sans vérité" que consiste en "faire la vérité" (\$27), observa Derrida en "Circonfession". Lo confesado jamás se reduce a decir la verdad, la verdad esencial de la confesión no tiene nada que ver con la verdad (\$49). La innovación que Derrida, como exponente de los autores agustinianos mentados, aporta a las teorías de la escritu- 
ra de sí y a la concepción del autor, consiste en definitiva en señalar que la confesión no es una enunciación constatativa, sino una performativa. Lejos está de describir una realidad; antes bien, la produce. Se hace algo cuando uno se confiesa, la verdad acontece, de alguna forma, en la escritura, como ya señalaba Kierkegaard. En esta misma línea de lectores agustinianos, Zambrano observa en La confesión: género literario que

la confesión parece ser una acción que se ejecuta no ya en el tiempo, sino con el tiempo; es una acción sobre el tiempo, mas no virtualmente, sino en la realidad. [...] Pero es que la Confesión es ejecutiva en algún otro sentido; alcanza algo que quiere transmitir; cuando leemos una Confesión auténtica sentimos repetirse aquello en nosotros mismos, y si no lo repetimos no logramos la meta de su secreto. $(1995,30)$

A su vez, Derrida sostiene que siempre que se confiesa algo, se trata de lo inconfesable, de lo imposible $(2000,17)$. La verdad de la confesión, observa Derrida, "es que hay que hacer lo imposible, y lo imposible sería quizá la única medida de todo 'hay que'"' (31). Esa verdad que se hace y que acontece en la confesión es, en la obra de Derrida, tan imposible como urgente, resulta una exigencia si el sí mismo ha de ser algo más que un relato de vida privada. La confesión, por ello, es un gesto performativo de transformación de sí, de ruptura del relato de sí, y solo en esa ruptura puede hacerse una verdad, solo así puede ocurrir algo. La escritura interrumpe, no conforma, valoraríamos con Derrida. En sus propios términos: "si ce livre ne me transforme de fond en comble, s'il ne me donne pas le sourire divin devant la mort, la mienne et celle des aimés, s'il ne m'aide pas à aimer plus encore la vie, il aura échoué" (1991, §15).

Además, cabe añadir que, en el pensamiento de Derrida, si la confesión tiene un carácter performativo, ello se debe a su vinculación con la promesa y el perdón. Toda confesión es una promesa, una demanda de confianza y el anuncio de que se va a 
decir algo verdadero, diríamos con él. En una confesión, uno no se compromete con el pasado, sino que "s'engage vers l'avenir" (1992, 220): ha de ocurrir algo imprevisto e incalculable para que una confesión sea tal cosa, y en este punto la confesión ya no es escritura autovigilante o ideológica, sino un espacio de experiencia. Uno hace su confesión no para susurrar el pecado vergonzoso ni regodearse en su culpabilidad, apuntaríamos con Derrida, Zambrano, Kierkegaard o el propio Agustín, sino porque busca una transformación, una liberación de un relato de sí asfixiante; invoca en la confesión un porvenir que subvierta el estado de cosas. En ese sentido Derrida observa que su confesión son las "memorias de un amnésico" (1991, § 19): no se trata de recordar nada, sino de imaginarse otro, de deshacer la historia.

En este punto, y en aras de valorar en su especificidad este paradigma alternativo del autor y de la confesión, es preciso recordar uno de los rasgos principales de la concepción derridiana del performativo. Tanto en Marges de la philosophie (1972) como en Limited Inc (1990), Derrida insiste en que, para que algo así como un performativo tenga lugar, y se hagan cosas con palabras, es preciso tener en consideración que el lenguaje obtiene la fuerza con que actúa al citar unas convenciones y unos usos históricos de la palabra. Si no es cita, si no es repetición, el lenguaje no puede ser performativo, en suma. Pero esta repetición del signo tiene la forma de una iteración: en tanto que un signo se repite y se extrae de un contexto pasado para injertarse en un nuevo espacio de habla, necesariamente se altera: se repite y se altera al mismo tiempo. De ahí que Jerade haya señalado que la performatividad derridiana se caracteriza por una "pervertibilidad estructural" (2019). Con ello, si, como ya señalara famosamente Austin (1971), todo lenguaje es performativo - porque, aunque no lo explicite, siempre declara, afirma o promete-, en Derrida la escritura es a la vez promesa - promesa de que algo llega, compromiso con el porvenir - y perjurio: quien habla no tiene control sobre los significados nuevos o inesperados que traerá consigo la 
repetición de aquello que cita, queda fuera de su alcance una alteridad potencial de sentidos o matices de sus palabras. En suma, no puede sino frustrar la promesa en el mismo gesto en que la hace. Derrida condensa este aprendizaje en una sencilla frase: “je parjure comme je respire" $(2012,72)$. Uno se compromete con la verdad al hablar, pero asume a su vez que faltará a su promesa porque hay una parcela del lenguaje que es estructuralmente incontrolable y aleatoria.

De ahí que, como ha explicado con precisión Manrique (2012), la teoría del performativo evoluciona en Derrida hacia una política del acontecimiento: cuando se hacen cosas con palabras, se alberga en ellas la oportunidad para lo inesperado, lo imprevisible y lo incalculable, aquello menos probable y más inaudito. En cada palabra aguarda la venida de lo otro, de una alteridad radical y aleatoria que, al acontecer, solo puede recibirse y padecerse, sin preparación ni aviso. Por ello, a su vez, diversos comentaristas, entre ellos Hillis Miller (2001, 159160), hayan destacado que esta pervertibilidad estructural del performativo y este encuentro con lo otro tengan como resultado una recuperación de la dimensión pasiva de los actos de habla que a sus teóricos anteriores les había pasado desapercibida. En su dimensión performativa, la escritura invoca, antes que una fuerza productiva, una fuerza de ruptura, diríamos siguiendo a Derrida: antes una interrupción que una constitución. Así pues, si observamos la cuestión que nos ocupa a la luz de los aportes derridianos a la teoría del performativo, la verdad de la confesión no es exactamente una verdad que se 'hace', como toda la tradición de agustinianos resalta, sino más bien una verdad que se 'padece': un acontecimiento de la verdad, una verdad que alguien dice de sí mismo y que, paradójicamente, adviene en el momento en que se escribe, siendo antes del todo desconocida. Quien se confiesa revela pues en las palabras algo que, en su completa extrañeza y desconocimiento, le pertenece, sale de su boca y conforma su intimidad, observaríamos con Derrida. De ahí que este acontecimiento de la verdad que tiene lugar en la 
escritura autobiográfica sea algo más que un performativo, algo más que producir una verdad o constituir una interioridad con el solo hecho de nombrarla, como querría Foucault. Así lo explica Derrida en "Composing Circonfession":

What characterizes an event is precisely that it defeats any performativity, that it happens, precisely, beyond any performative power. So what couldn't be accounted for in "Circumfession" is not something that I would have organized in order to challenge or to defeat Geoff 's “Derridabase." It was something which would happen to me without any possibility for me to anticipate, to predict, to foresee, or to perform. It is this limit of the performativity that in fact draws the line we are now analyzing. The interest we are taking in speech act theory in the academy perhaps has to do with the illusion that, by using performative utterances, we produce events, that we are mastering history. The event is absolutely unpredictable, that is, beyond any performativity. That's where a signature occurs. If I so much insist on circumcision in this text, it is because circumcision is precisely something which happens to a powerless child before he can speak, before he can sign, before he has a name. (En Caputo y Scanlon, 2005, 20-21)

No hay forma de determinar la promesa de un porvenir, no hay manera de cerrar lo que la escritura abre, sostiene Derrida. La confesión es un espacio de encuentro con la alteridad, de extrañamiento y de alteración. Solo así es algo más que relato, algo más que disciplina y que conocimiento, pues se torna experiencia. De esta forma, Derrida no solo se distancia de los autores más arriba mentados, sino que también se desmarca de la propuesta de Lejeune (1994) del pacto autobiográfico, mediante el que la escritura de sí se caracteriza por el vehemente compromiso del

3 Además de los estudios citados sobre la performatividad en la obra de Derrida, puede resultar esclarecedor el trabajo de autores como Moati (2014), Didderen (2006) o Navarro Reyes (2010), y, especialmente por su notable actualidad, la compilación de Senatore (2013) y su introducción a la misma. 
autor de desproveer de ficción las páginas que siguen y adecuar por completo a la realidad el yo que se narra. En la perspectiva que Derrida nos brinda, más allá de lo que el autor quiera o prometa, no puede haber algo así como un puro pacto autobiográfico, no puede darse lugar a algo así como una promesa que se realice perfectamente en las palabras de la autobiografía. Antes bien, para que una confesión digna de ese nombre tenga lugar, y no se reduzca a una mitificación del yo o a una vigilancia autoinducida, ha de reconocerse que no puede haber compromiso biográfico, sino solo perjurio de la autobiografía. Sostener el modelo del pacto, pese a que efectivamente toda confesión, como todo texto, guarde una promesa de verdad, conllevaría someterse a la ilusión del carácter representativo de la escritura y del carácter sustancial y distinto de una vida contrapuesta a una obra. Con Derrida, estimamos que ello no solo no es posible de forma pura y resuelta, sino que, por lo expuesto en el apartado anterior, no es deseable. "Une confession ne fait pas la vérité", precisa en su circonfesión, "elle doit m’affecter, me toucher" (1991, §15). En consecuencia, las políticas de la confesión que Derrida inaugura se diferencian de las propuestas anteriores tanto por el desplazamiento del ámbito del conocimiento al de la experiencia, como por la impugnación de la agencia performativa en aras de abrazar una concepción acontecimental de la confesión. Este segundo desplazamiento, y en esto consiste la disintonía con Lejeune, también consiste en reconocer la escritura confesional como un espacio de pasividad y vulnerabilidad, y no tanto un espacio de acción y soberanía.

En línea con esta peculiar dimensión performativa que Derrida otorga a la confesión, se pone de manifiesto un elemento clave para comprender su dinámica textual: toda confesión siempre va dirigida a alguien, siempre mantiene un pulso con la alteridad (sea Dios, sea el lector, sea uno mismo, sea cualquiera, cualquier otro). En la escritura de sí, el yo se relaciona consigo mismo, pero esta vuelta sobre sí implica una instancia de alteridad que desajusta la presunta indivisibilidad y el carácter unitario de quien escribe. El 
yo se desordena en la confesión, se hace vulnerable. En tanto que dirigida a cualquiera, por escrita, la confesión guarda en su seno un momento de indeterminación que hace posible que algo ocurra, que 'pase' algo distinto, que el texto difiera de sí y transforme su significado. Reconoce así Derrida en "Circonfession" queél mismo no sabe cuál es ese enigma indecible que sustenta su confesión y que, al tiempo, la imposibilita como relato: "j'aurai continué à tourner autour", dice, "sans savoir le secret de ma souffrance" pese a la tentación de "interpréter [ma vie] à partir de quelque vérité rassurante" (1991, §15). Si la confesión derridiana, como se señalaba más arriba, no se dirige al pasado, sino al avenir, ello se debe a que, además de realizar una verdad incógnita, su valor y su sentido - esto es, su pregnancia performativa -, cambiarán en función de quién se torne el destinatario del texto. La confesión, podría decirse, es lo más íntimo; pero en tanto escritura, es lo más público. La singularidad y lo anónimo, lo íntimo y lo extraño, se entrelazan y contagian en las escrituras de sí que Derrida piensa, y ello confiere tanto a la confesión como a la figura autorial un paradójico estatuto que se encontraba ausente en las teorías contemporáneas que en este estudio se han expuesto, y que redirige constantemente el problema de la subjetividad y el problema de la lectura a la cuestión de la alteridad y, por ello, de la política.

Toda confesión, de esta forma, guarda un secreto y decepciona tanto en su promesa de contar algo del pasado a lo que anclar la referencia del texto, como en la hipotética empresa de producir un sujeto normalizado futuro - ambas caras de la confesión como autobiopolítica, como relato de sí que no está atravesado por la alteridad-. En cambio, a partir de la valoración derridiana de la confesión, uno no sabe lo que escribe - desde luego, tampoco lo que lee-, hasta después, hasta que ocurre algo. La confesión guarda un secreto, que es la indeterminación o la indecibilidad de su apertura como texto. Como toda literatura, su potencial radica no en la polisemia, sino en una falta de sentido, o un sentido en falta: la confesión no llega a decir nada, y por 
ello mismo, no solo es promesa o perjurio, sino también un gesto de perdón. De nuevo, es un perdón imposible, el único digno de su nombre según Derrida, un perdón de lo imperdonable, de un imperdonable indefinido: perdón por no querer decir, por no manifestarse, perdón por guardar el secreto: perdón, en suma, por sacrificar el régimen de comunicabilidad. La confesión que concibe Derrida, en sus propias palabras, es

una confesión singular, inaudita, improbable, una confesión que, antes y más allá de toda falta determinada, declara ante el otro lo inconfesable. Pues confesar lo que parece fácil confesar, confesar lo confesable, reconozcámoslo, una cosa así no sería confesar. Confesémoslo. La confesión, si la hay, debe confesar lo inconfesable, y en consecuencia, declararlo. La confesión tendría que declarar, si fuese posible, lo inconfesable, es decir, lo injusto, lo injustificable, lo imperdonable, hasta la imposibilidad de confesar. Del mismo modo, perdonar sólo lo que es perdonable, venial, algo así no sería perdonar. La confesión, si la hay, tiene que confesar lo inconfesable, y el perdón, si lo hay, tiene que perdonar lo imperdonable, y en consecuencia, hacer lo imposible. $(2000,18)$

Del mismo modo en que Pardo pensaba con la intimidad ese espacio personal de resistencia a la manifestación y a la identificación, Derrida concibe esta huella de la alteridad en el seno de uno mismo mediante el concepto de 'secreto', un concepto recurrente en la obra del filósofo que autores como Lisse (1999) o Michaud (2006), clásicamente, o Barbour en un texto reciente (2017), se han preocupado por diseccionar. Este secreto de la confesión es un "no saber estructural" (Derrida, 1992, 215): no se trata de una información oculta, sino de "una experiencia que no se libra a la información" (ídem): algo ocurre, algo nos pasa en la escritura, y, aunque inscrito, no está configurado como saber: "personne ne saura jamais à partir de quel secret j'écris", apunta Derrida, "et que je le dise n'y change rien" (1991, §39). Derrida gusta de comparar la literatura en Donner la mort (1999) con un meteorito: su destello en 
el cielo, su hacerse legible, solo revela la ilegibilidad de su origen y de su destino: en la confesión se lee esa ilegibilidad de la vida clandestina agambeniana, se asiste y se experimenta una alteración y una falta. Con ello, como sostiene Lyotard, "la autobiografía (de haber una) se transforma en criptografía" $(2002,109)$.

Para estos pensadores, toda autobiografía es tanto la confesión de un secreto como una heterobiografía, la biografía de otro, el relato de mi vida como una producción extraña, mi encuentro con mi vida saliendo de ella, dándole palabras. Y de ello da cuenta la estructura del libro en que Derrida incluye su confesión. Esta se despliega en una suerte de "marge intérieure" $(1991,5)$ de un libro firmado por Geoffrey Bennington y titulado Jacques Derrida que supone una biografía intelectual del pensador. Además, la obra se compone de otras formas de escritura de sí, como lo es el curriculum vitae, una enumeración de las fechas relevantes de la vida de Derrida, y una nutrida colección de fotografías personales y de imágenes preferidas. La confesión, que se despliega en la parte inferior de las páginas, interrumpe y cuestiona la legitimidad y el alcance de estas otras escrituras de sí en su papel de decir la verdad sobre uno mismo o dar conocimiento del filósofo. Como margen interior a estos discursos, la confesión de Derrida es, como diría Lyotard, "una grieta" que "atraviesa en zigzag todo lo que se ofrece a la escritura" $(2002,82)$, y marca la insuficiencia de los biorrelatos para alcanzar la experiencia del secreto que toda escritura de sí debería de abordar.

Estas cuestiones apuntan hacia uno de los elementos más marcadamente políticos de la escritura confesional en Derrida: y es que, lejos de constituirse en su autonomía, el sujeto que se confiesa, justamente por girar en torno a un secreto que se padece como el acontecimiento de la verdad, se heteronomiza, es sometido a la ley del otro. Es decir, la soberanía del sujeto moderno se ve resquebrajada, partida, por el momento de alteridad y escritura que son constitutivos de la confesión. Esa escritura y esa apertura de la alteridad que son imprescindibles para que el sujeto se relacione consigo mismo, para conformar en suma el autos del sujeto 
'autónomo', tornan a su vez imposible una tal constitución. En la vuelta a sí mismo del sujeto que se quiere re-flexionar y autoconocer, hay una interrupción, una división, un momento secreto, separado (se cernere) que priva al yo de su poder, que le desapropia en el momento mismo en que lo posibilita. Como observa con acierto Odello $(2017,153)$, es este poder del sujeto, que radica en la indivisibilidad y continuidad de su relación consigo mismo, en el s'entendre-parler de la voz, la primera soberanía que Derrida, ya a finales de los sesenta, se afanó en deconstruir: la crítica a la soberanía del estado o a otras instancias de poder absoluto pretendidamente más políticas que se abordan en los 90 no serían sino ampliaciones de esta crítica a la autoridad y al poder inherentes a la concepción moderna del sí mismo, de la mismidad o 'ipseidad'. Así lo valora el propio Derrida en Voyous:

Avant même toute souveraineté de l'État, de l'État-nation, du monarque ou, en démocratie, du peuple, l'ipséité nomme un principe de souveraineté légitime, la suprématie accréditée ou reconnue d'un pouvoir ou d'une force, d'un kratos, d'une cratie. Voilà ce qui se trouve donc impliqué, posé, supposé, imposé aussi dans la position même, dans l'auto-position de l'ipséité même, partout où il y a du soi-même. $(2003,32)$

Es esta primera soberanía de la ipseidad la que está en cuestión en el género de la confesión cuando de lo que se trata es de hacer una verdad que se padece, y una verdad que no forma parte del régimen de la verdad, sino que resulta ilegible, solo experimentable. La autoridad del autor queda desarticulada por el propio texto, es el texto el que produce esa posición y, al tiempo, la torna inviable como una clave de comprensión o una referencia de sentido. Lo que enseña el pensamiento de Derrida es que el texto es un espacio de desposesión, de división y de encuentro con el otro, nunca de autoposición, de autoridad o de reafirmación. El autor, como ya hiciera Kierkegaard, se mira en el espejo de su texto y no se reconoce (Garff, 2003). Pero es esta confronta- 
ción lo que le transforma, lo que permite desbaratar la policía de la normalización y la mitología de la interioridad para inaugurar un espacio de micropolítica y de cuidado de sí.

En su política de la confesión, Derrida lleva hasta sus límites esta idea del secreto, la separación, la alteridad o la soberanía dividida. No en vano su texto es una circuncisión: este secreto del que se escribe, y que se desconoce, es concebido por Derrida, como ya lo fue por Zambrano $(1965,32)$, como una "herida" o una "escara" (Derrida, 1991, §16). El autor no estaba muerto, el sujeto no había desaparecido, pero sí estaban heridos de muerte: esta encarnación del secreto y de la huella del otro como "herida" marca una nueva forma de pensar no solo la subjetividad que se ensaya en una confesión si no, más generalmente, la figura misma del autor. La herida que se padece en una confesión lleva a Derrida a comparar el flujo de escritura con la sangre que se vierte: "si ça ne saigne pas, le livre sera manqué" (1991, §25). La escritura confesional es un brotar de sangre, la pluma es una jeringuilla que quiere "encontrar la vena" y dejar correr "la palabra cruda" (1991, §2). La vida del autor está así implicada hasta en su sangre en lo que escribe, no hay así una disyuntiva entre la escritura o la vida, ni una correlación entre ambas, sino que su secreto común yace en la misma inscripción, en el mismo enigma sin llave: la escritura es un resto de vida, es una secreción o una prolongación del cuerpo. La política derridiana de la confesión es, así, una política de la sangre, una política de las heridas incurables. ${ }^{4}$

De esta forma, si siempre que se escribe está en juego este secreto y esta herida, si escribirse es alterarse y padecerse, la cues-

4 Cuestiones de espacio nos impiden ahondar más en este motivo de la sangre, metáfora estructural de la circunfesión de Derrida y tema recurrente en su seminario sobre la pena de muerte. La sangre permite, en Derrida, desplegar un pensamiento del tiempo y la vida en su relación con la soberanía, que se piensa en ocasiones como crueldad (sangre estancada, vertimiento de sangre legitimado, sangre formalizada, conceptualizada, justificada) y en otras como flujo de sangre, como el de la confesión (tiempo sin tiempo, sobrevida, discontinuidad de la experiencia). Véase, para todo ello, el interesante capítulo de Wills sobre la sangre en su Killing Times (2019, 88 y ss.). 
tión no es ya qué es una confesión o qué es una autobiografía, sino antes bien ¿Cómo no confesarse? ¿Cómo no autobiografiarse? "Comment ne pas parler de soi ? Mais aussi bien, comment le faire sans se laisser inventer par l'autre? ou sans inventer l'autre ?", al decir de Derrida $(1987,543)$ Toda nuestra escritura es una confesión, una confesión de algo imposible de confesar, de algo que desconocemos, de algo que ni imaginamos. Toda literatura, abundará Derrida, alberga una herida: "pas de poème qui ne s'ouvre comme une blessure, mais qui ne soit aussi blessant", afirmará en Points de suspension $(1992,307)$. E insiste en otra parte: "the signature of a poem, like that of any text, is a wound. What opens, what doesn't heal [ne cicatrise pas], the hiatus, is indeed the mouth that speaks where it is wounded" (Derrida y Grossman, 2019, 20; énfasis nuestro). La boca del poema, por donde habla, es a la vez su herida, esto es, la huella del otro. Todo el pensamiento del motivo autobiográfico en Derrida pasa por hacer de la escritura un lugar de encuentro con el otro, un desorden, una “desfiguración”, al decir de De Man (1991).

Y por estas heridas y estos ataques de muerte, no se trata nunca, en el porvenir de una confesión, de la vida del autor que la escribe. La vida queda en el currículum, en los algoritmos de Google, en la calculabilidad de lo que se hace en privado o en público. El autor que se confiesa se comprende a sí mismo como superviviente, como alguien que ha sobrevivido a la ausencia y la muerte que la escritura le imponía. En la vida después de la muerte de la escritura hay algo así como un plus de vida, un añadido inesperado e incodificable de vida, una vida atravesada por la alteridad, herida de muerte. Una survie o sobrevida, un exceso de vida inesperado, improbable e imposible. También por eso, por ser supervivientes, por quedar todavía vivos y haber sacrificado al otro, al sentido, al lenguaje, también por ello se pide perdón en la confesión. Si decía el escritor "je parjure comme je respire", dice también quien se confiesa "je posthume comme je respire" (1991, §28). En todo ello se muestra un rasgo sorprendente y difícil de pensar en la propuesta derridiana: escribir es violentarse, pero 
también es abrazar una forma de vida más alta y más intensa, un plus de vida al que el poder o la soberanía no alcanzan. Es esta la oportunidad que subyace en cada confesión, y también el tesoro de la literatura: el padecimiento, la vulnerabilidad. Así definía Derrida la sobrevida en una de sus últimas entrevistas:

Nous sommes structurellement des survivants, marqués par cette structure de la trace, du testament. Mais, ayant dit cela, je ne voudrais pas laisser cours à l'interprétation selon laquelle la survivance est plutôt du côté de la mort, du passé, que de la vie et de l'avenir. Non, tout le temps, la déconstruction est du côté du oui, de l'affirmation de la vie. Tout ce que je dis [...] de la survie comme complication de l'opposition vie/mort, procède chez moi d'une affirmation inconditionnelle de la vie. La survivance, c'est la vie au-delà de la vie, la vie plus que la vie, et le discours que je tiens n'est pas mortifère, au contraire, c'est l'affirmation d'un vivant qui préfère le vivre et donc le survivre à la mort, car la survie, ce n'est pas simplement ce qui reste, c'est la vie la plus intense possible. $(2005,54-55)$

\section{Nota final. Hablan las heridas}

La carne no tiene los medios para pensar, solo experimenta. Jean-François Lyotard (2002)

En suma, la propuesta derridiana de autobiografía, muy afín a las de autores como Kierkegaard, Zambrano o Lyotard, destaca por su carácter performativo, su invocación de la alteridad, su destitución de la soberanía de la ipseidad, por su generalización y contaminación de otras formas de escritura y por esa sobrevida que cuestiona la unicidad y la comunicabilidad de una vida-relato. No es policial la confesión, sino una exigencia de la vida inenarrable, de su intensidad clandestina: y así, se vuelve una experiencia política del acontecimiento, una apertura a la alteridad y un espacio de destitución de la soberanía. No es solo una autobiopolítica, sino fuerza de una vida atravesada por la 
alteridad y por la muerte, instalada en sus heridas. Así, el autor vive tras su muerte, sobrevive como un texto, como una lectura, como un espectro o una herida.

Las reflexiones de Derrida acerca de la generalización de la autobiografía y la sobrevida permiten pensar la cuestión del autor desde tres nuevas perspectivas, todas ellas más allá tanto de la vida del autor como de 'la muerte del autor'. Se caracterizan por cuestionar la distinción entre vida y obra y pensar el texto, en suma, como parte del cuerpo del escritor, que se torna una autoría encarnada. En esta línea, Sàez Tajafuerce ha observado que el autor adquiere un carácter espectral: ni vivo ni muerto, ni puramente ausente ni plenamente presente, es aquella instancia que supone la condición de posibilidad y de imposibilidad del trabajo del texto, una instancia secreta que anima el decir y, a la vez, lo atrofia. Escribe Sàez Tajafuerce:

El autor se ve emplazado, entonces, como lo hiciera la enunciación, a un lugar intermedio que va a determinar las relaciones con la obra y, así, la instauración discursiva misma como interés qua inter-esse, es decir, como 'ser entre'. El estatuto de la nueva ausencia del autor radica en esa determinación intermedia como lugar (im)propio de una economía otra. Así como la obra deviene excedente, el autor deviene espectro. Para ambos casos rige la ejemplar puesta en obra de lo espectral. $(2015,161)$

En la misma línea, Cróquer Pedrón ha observado que la autoría "no funda ni instaura discursividad alguna", sino que más bien "la desborda" y "la desquicia" $(2012,91)$. Lo relevante y sorprendente de estas contribuciones es que el carácter espectral del autor coincide con su encarnación como texto: la ilegibilidad se declina como carne y materia del texto - como lo que, en el texto, excede la codificación- y como aparición-desaparición, holograma o imagen entre la vida y la muerte, la presencia y la ausencia. Continúa Cróquer Pedrón para indicar que, con ello, lo que se busca pensar es "una productividad donde lo 'Real' de la 
vida del 'creador' (la dimensión más física de su cuerpo y/o de las pulsiones que lo atraviesan) deviene indiscernible del producto de su 'trabajo creativo'; y donde esa obscena imposibilidad de discernir se hace pública" $(2012,93)$.

En paralelo, Pérez Fontdevila sentencia sin rodeos: “El autor es el libro, el cuerpo es el corpus, se mire por donde se mire" (2015, 105). También Torras Francès participa de esta línea que piensa la autoría como carne y como espectro, y que rompe con el carácter representativo o cognoscitivo de la escritura de sí:

the work-author couple not only hides a tautology in itself (one that is defined by the other one, like a Möbius strip) but also, within these pair, bodily attributes are bodily transferred in a bidirectional way. This is why the mark of literacy that the author conveys to his or her works is engraved in author's faces, together with the unity of meaning, the integrity, the entireness, and the singularity that is inflicted on it. $(2015,52)$

Así, y en tercer lugar, del mismo modo que los textos experimentan una suerte de devenir-cuerpo autorial, la figura del autor experimenta una cierta textualización: todo aquello que compone la imagen del autor es ya un texto suyo y una biografía o autobiografía, supone ya una inscripción y una escritura de su cuerpo: es lo que Lisse pensó como “iconografía” (2009) al reflexionar sobre la relación de Derrida con sus fotografías, o lo que Torras Francès y Pérez Fontdevila han concebido como "corpografía" (2017). Nunca el autor había estado tan vivo, nunca tan muerto.

En definitiva, la teoría de la confesión que brinda Jacques Derrida supone tanto la redefinición del género literario como la apertura de una nueva forma de pensar la autoría, en que el recurso a la corporalidad y a la alteridad adquieren un papel clave en la elaboración de una política textual. Con ella, la literatura sigue brindando oportunidades para el pensamiento crítico, sea bajo la forma de la indisciplina o bajo la forma del desvelamiento de ideologías. No hay nada que interpretar o que leer fuera de un 
texto, la vida misma del autor está allí, no hay ni un afuera ni una interioridad que buscar. Nada por leer, todo por experimentar. Si algo murió con la muerte del autor, es una cierta forma de metafísica de la lectura, una instancia de soberanía que organizaba el sentido del texto de forma unívoca y total. Si algo vive tras esa muerte, es un encuentro otro con los textos, una experiencia de la lectura como apasionamiento y transformación, como interrupción de la identidad. Las palabras de Blanchot resuenan con fuerza de nuevo: el autor afronta su tarea "como si la muerte fuera de él no pudiese desde entonces más que chocar con la muerte en él. ‘Estoy vivo. No, estás muerto'” $(1999,25)$.

\section{Referencias bibliográficas}

Adorno, Th. W. y Horkheimer, M. (2007) Dialéctica de la Ilustración. Fragmentos filosóficos, Madrid, Akal.

Agamben, G. (2017) El uso de los cuerpos. Homo sacer, IV, 2, Buenos Aires, Adriana Hidalgo editora.

Agustín (2017) Confesión, Barcelona, Austral.

Asensi, M. (2006) Los años salvajes de la teoría: Ph. Sollers, Tel Quel, y la génesis del pensamiento post-estructural francés, Valencia, Tirant lo Blanch.

Austin, J. L. (1971) ¿Cómo hacer cosas con palabras?, Barcelona, Paidós.

Barbour, C. O. (2017) Derrida's Secrets. Perjury, Testimony, Oath, Edimburgo, Edinburgh University Press.

Barthes, R. (1984) Le bruissement de la langue. Essais critiques IV, París, Éditions du Seuil.

Blanchot, M. (1999) El instante de mi muerte. La locura de la luz, Madrid, Tecnos.

Burke, S. (1992) The Death \& Return of the Author. Criticism and Subjectivity in Barthes, Foucault and Derrida, Edimburgo, Edinburg University Press.

Caputo, J. D. y Scanlon, M. J. (eds.), (2005) Augustine and Postmodernism. Confessions and Circumfession, Bloomington, Indiana University Press. 
Cróquer Pedrón, E. (2012) “Casos de autor: anormales/originales de la literatura y el arte (II). Allí donde la vida (es) obra", Voz y Escritura. Revista de Estudios Literarios, 20, 89-103.

De Man, P. (1991) “La autobiografía como desfiguración”, Anthropos: Boletin de Información y Documentación, Extra 29, 113-118.

Derrida, J. (1967) La voix et le phénomène, París, PUF.

Derrida, J. (1972) Marges de la philosophie, País, Éditions de Minuit.

Derrida, J. (1987) Psyché. Inventions de l'autre, París, Galilée.

Derrida, J. (1990) Limited Inc, París, Galilée.

Derrida, J. (1991) “Circonfession”, en Bennington, G., Jacques Derrida, París, Seuil.

Derrida, J. (1992) Points de suspension, París, Galilée.

Derrida, J. (1998) "A corazón abierto. Entrevistas en France Culture con Catherine Paoletti". Obtenido el 05/05/2019 en https://redaprenderycambiar.com.ar/derrida/textos/corazon.htm.

Derrida, J. (1999) Donner la mort, París, Galilée.

Derrida, J. (2000) “Confesar - Lo imposible. 'Retornos', arrepentimiento y reconciliación", Isegoría, 23, 17-43.

Derrida, J. (2003) Voyous. Deux essais sur la raison, París, Galilée.

Derrida, J. (2005) Apprendre à vivre enfin. Entretien avec Jean Birnbaum, París, Galilée / Le Monde.

Derrida, J. (2012) Pardonner. L'impardonnable et l'imprescriptible, París, Galilée.

Derrida, J. y Grossman, E. (2019) “The Truth that Hurts, or the Corps à Corps of Tongues", Parallax, 25, 1, 8-24.

Didderen, D. (2006) "Itérabilité et parasitisme: Essai sur le débat entre Searle et Derrida autour du langage et de l'intentionnalité", Bulletin d'Analyse Phénoménologique, 2, 4, 3-182.

Foucault, M. (1963) Raymond Roussel, París, Gallimard.

Foucault, M. (1994) “Qu'est-ce qu'un auteur ?", en Dits et écrits, tomo I, París, Gallimard, 789-821.

Foucault, M. (1996) Tecnologías del yo y otros textos afines, Barcelona, Paidós / I.C.E.-U.A.B. 
Foucault, M. (2015) Naissance de la clíniques, París, PUF.

GARFF, J. (2003) “'What did I find? Not my I'. On Kierkegaard's Journals and the Pseudonymous Autobiography", Kierkegaard Yearbook 2003, 110-124.

Hillis Miller, J. (2001) Speech Acts in Literature, Stanford, Stanford University Press.

Jerade, M. (2019) “Repolitizando las diferencias. Derrida y la teoría de los actos de habla", Isegoría, en prensa.

KierkegaArd, S. (2010) Discursos edificantes. Tres discursos para ocasiones supuestas. Escritos Søren Kierkegaard 5, Madrid, Trotta.

Kracauer, S. (2008) La fotografía y otros ensayos. El ornamento de la masa 1, Barcelona, Gedisa.

Lejeune, Ph. (1994) El pacto autobiográfico y otros estudios, Madrid, Megazul-Endymion.

Llevadot, L. (2012) “La intimitat: de la privacitat del jo a l'escriptura de sí", Comprendre, 14, 1, 5-19.

Llevadot, L. (2015) “Hacer la verdad: El 'yo' de la confesión en Kierkegaard, Foucault y Derrida", Estudios Kierkegaardianos. Revista de Filosofía, 1, 149-168.

Lisse, M. (1999) “Le secret exemplaire de la littérature", en Zabus, Ch. (ed.), Le secret : motif et moteur de la littérature, Louvainla-Neuve, Université de Louvain, 424-436.

Lisse, M. (2009) "Iconographies de Jacques Derrida", en Dewez, N. y Martens, D. (eds.), "Iconographies de l'écrivain", Interférences Littéraires, 2, 257-263.

Luque Amo, Á. (2017) “Literatura y autobiopolítica: aportaciones de Michel Foucault a la teoría de la autobiografía", 452 ${ }^{\circ} F$, $17,18-35$.

Lyotard, J.-F. (2002) La confesión de Agustín, Buenos Aires, Losada.

Manrique, C. A. (2012) “El desplazamiento del concepto derridiano de 'performativo': de la iterabilidad de la escritura a la singularidad de la justicia", Natal, 19, 32, 301-330.

Matas Pons, À. (2015) “Falseamiento y consumo de la identidad, de Rousseau a Adorno", Isegoría, 53, pp. 631-646. 
Michaud, G. (2006) Tenir au secret (Derrida, Blanchot), París, Galilée.

MoAti, R. (2014) Derrida/Searle. Deconstruction and Ordinary Language, Nueva York, Columbia University Press.

Navarro Reyes, J. (2010) Cómo hacer filosofía con palabras. A propósito del desencuentro entre Searle y Derrida, Madrid, Fondo de Cultura Económica.

Nietzsche, F. (1979) Más allá del bien y del mal, Madrid, Alianza.

Odello, L. (2017) “'The greatest possible mastery, the greatest possible self-presence of life': Derrida and the Deconstruction of Sovereignty", CR: The New Centennial Review, 17, 1, 141-162.

Pardo, J. L. (1996) La intimidad, Valencia, Pre-Textos.

Pérez Fontdevila, A. (2015) “'Algo me mira sin verme'. Una introducción miope a la cuestión del autor", Tropelías. Revista de Teoría de la Literatura y Literatura Comparada, 24, 100-123.

Pérez Fontdevila, A. y Torras Francès, M. (2017) “Authorial Corpographies. Performing Gender and Cultural Authorship", Interférences Littéraires, 21, 3-21.

Roussel, R. (1963) Comment j'ai écrit certains de mes livres, París, Jean-Jacques Pauvert.

Sàez Tajafuerce, B. (2015) “Del autor como espectro o de la fantomaquia. Del arte de lidiar (con) fantasmas", Tropelías. Revista de Teoría de la Literatura y Literatura Comparada, 24, 157-164.

Senatore, M. (2013) "Introduction: Positing, the Performative and the Supplement", en Senatore, M. (ed.), Performatives after Deconstruction, Londres, Bloomsbury, 1-42.

Torras Francès, M. (2015) "Tracing the author or how theory constitutes an auto(bio)graph", en Balaguer, E. et al. (eds.), An Approach to the Other. Biographies, Resemblances, and Portraits, Ámsterdam, John Benjamins Publishing Company, 49-57.

Wills, D. (2019) Killing Times. The Temporal Technology of the Death Penalty, Nueva York, Fordham University Press.

Wittgenstein, L. (1997) Conferencia sobre ética. Con dos comentarios sobre la teoría del valor, Barcelona, Paidós / IC.E. - U.A.B. 
Wittgenstein, L. (2003) Tractatus Logico-Philosophicus, Madrid, Alianza.

Zambrano, M. (1965) "La ambigüedad de Don Quijote", en España, sueño y verdad, Madrid, Siruela, 30-37.

Zambrano, M. (1995) La confesión: género literario, Madrid, Siruela. 